\title{
COMPORTAMENTO ALIMENTAR DE AVES EM MICONIA RUBIGINOSA (MELASTOMATACEAE) EM FRAGMENTO DE CERRADO, SÃO PAULO
}

\author{
Luiz Octavio Marcondes-Machado ${ }^{1}$
}

\begin{abstract}
AVIAN FORAGING BEHAVIOR ON MICONIA RUBIGINOSA (MELASTOMATACEAE) IN CERRADO FRAGMENT, SÃO PAULO. Birds of 11 species were observed feeding on fruits of Miconia rubiginosa (Bonpl.)DL between February and March 1985 in Itirapina cerrado, State of São Paulo, Brazil. The feeding strategies of birds with regards to fruit use, and the role of the fruits as food resources for the birds in cerrado are analyzed.
\end{abstract}

KEYWORDS. Avian frugivory, Cerrado, Melastomataceae, Miconia.

\section{INTRODUÇÃO}

As espécies de plantas da família Melastomataceae, como as do gênero Miconia Ruiz \& Pav., produzem frutos utilizados por diversas espécies de aves frugívoras, em particular por aquelas oportunistas (SNOw, 1981), algumas das quais encontradas no cerrado. Este ecossistema, no Estado de São Paulo, vem sofrendo uma contínua diminuição, representando em 1992 apenas $0,7 \%$ do território paulista, enquanto no início do século passado representava $18,2 \%$. Estes remanescentes do cerrado estão atualmente reduzidos a fragmentos disjuntos em áreas protegidas (CETESB, 1992).

Miconia rubiginosa ocorre desde a Costa Rica até a Bolívia e no Brasil. Encontrada em cerrados dos estados de Mato Grosso, Bahia, Minas Gerais e São Paulo. É um arbusto de aproximadamente $1 \mathrm{~m}$ de altura, podendo chegar a uma arvoreta de $5 \mathrm{~m}$. O fruto é uma baga violácea com poucas sementes por lóculo. As sementes possuem em média $10 \mathrm{~mm}$ de altura por 1,3 $\mathrm{mm}$ de largura na base (MARTINs et al., 1996).

Tendo em vista a importância das melastomatáceas para a fauna (HiLty, 1980), procurou-se avaliar o papel de Miconia rubiginosa (Bonpl.) DL para as aves que habitam o cerrado paulista, determinando quais espécies se alimentam dos seus frutos, qual o comportamento apresentado durante o forrageamento, como os frutos são consumidos e detectar quais entre elas poderiam ser mais eficientes como dispersoras de sementes.

1. Departamento de Zoologia, Universidade Estadual de Campinas (UNICAMP), Caixa Postal 6109, 13083-970, Campinas, SP, Brasil. 


\section{MATERIAL E MÉTODOS}

No cerradão da Estação Experimental de Itirapina, Instituto Florestal do Estado de São Paulo $\left(22^{\circ} 15^{\prime} \mathrm{S}-47^{\circ} 49^{\prime} \mathrm{W}\right)$, a uma altitude de $762 \mathrm{~m}$, as aves foram observadas com binóculo no período de 28 de fevereiro a 20 de março de 1985 , durante 5 sessões, num total de $10 \mathrm{~h} 15 \mathrm{~min}$ de observação. Das 5 sessões, 4 foram realizadas no período da manhã e uma no período da tarde, com a finalidade de se estudar a frugivoria em M. rubiginosa. Foram acompanhadas duas plantas, uma de $1,80 \mathrm{~m}$ e outra de $1,50 \mathrm{~m}$ de altura, situadas na beira de uma estrada que corta o cerradão.

A nomenclatura utilizada para as espécies de aves segue SiCK (1997) e com indicação das estratégias alimentares, segundo classificação proposta por Moermond \& Denslow (1985).

\section{RESULTADOS}

A frutificação de $M$. rubiginosa estendeu-se de meados de fevereiro até meados de abril de 1985 nos cerrados de Itirapina, SP. O número de visitas alimentares (va), "feeding bouts", realizadas pelos indivíduos das diferentes espécies de aves que se alimentaram de bagas de M. rubiginosa (tab. I), demonstrou que os espécimens de Elaenia flavogaster (Thunberg, 1822) (Tyrannidae, Elaeniinae) engoliram o fruto que estava próximo, inteiro, sem mascar $(\mathrm{va}=11)$. As espécies de Tyranninae como Pitangus sulphuratus (L., 1766) (va = 11), Myiodynastes maculatus $($ Müller, 1776) $(\mathrm{va}=8)$, Tyrannus melancholicus (Vieillot, 1819) $(\mathrm{va}=12)$ comportam-se de maneira semelhante, voando até o fruto, arrancando-o com o bico, voltando ao galho de onde partiu, ou em outro galho, e então engolem o fruto inteiro. Tyannus melancholicus pode também pousar sobre o cacho e em seguida comer frutos inteiros $(\mathrm{n}=8)$. Pachyramphus validus (=Platypsaris rufus) (Vieillot, 1816) (Tyrannidae, Tityrinae) utiliza método de apreensão de frutos semelhante à espécie anterior e engole o fruto inteiro $(\mathrm{va}=4)$.

Entre as espécies de Muscicapidae, Turdinae, o comportamento alimentar varia. Turdus rufiventris (Vieillot, 1818) pula de galho em galho e arranca os frutos $(\mathrm{n}=12)$ dos cachos que estão acima de sua cabeça, alongando-se para alcançá-los, engole os frutos inteiros, sem mascar. Pode também pousar no cacho e comer os frutos ( $\mathrm{n}=10$ a 18 ), que estão próximos $(\mathrm{va}=18)$. Turdus leucomelas $($ Vieillot, 1818$)$ pousa próximo ao fruto ou sobre o cacho, onde chega a comer sete frutos seguidos, engolindo-os inteiros. Apresenta também o comportamento de voar até um fruto, apreendê-lo com o bico e se deixa cair, arrancando-o, indo pousar em um galho próximo, onde o engole $(v a=24)$. Turdus amaurochalinus (Cabanis, 1851) voa até um cacho, pousa sobre ele, arranca um fruto próximo e o engole inteiro $(\mathrm{n}=4),(\mathrm{va}=13)$.

Ocorre também variação do comportamento nas espécies de Emberizidae, Thraupinae. Nemosia pileata (Boddaert, 1783) arranca um fruto próximo, esmaga com o bico, sacode a cabeça para os lados, deixando cair parte do fruto e engole o que sobrou. Repete a operação várias vezes $(\mathrm{n}=6),(\mathrm{va}=4)$. Thraupis sayaca $(\mathrm{L} ., 1766)$ pousa sobre um cacho, arranca os frutos $(\mathrm{n}=8)$ próximos, que amassa um pouco com o bico e os engole inteiros $(\mathrm{va}=13)$. Tangara cayana $(\mathrm{L} ., 1766)$ pousa sobre o cacho, arranca os frutos $(\mathrm{n}=6)$ próximos, masca, deixando cair a casca e engole o que sobrou $(\mathrm{va}=5)$.

Nas espécies onde consta um valor para $n$, este representa o maior número de frutos colhidos pela ave durante uma visita. As aves que se alimentaram pousadas nos cachos, ingeriram quantidade maior de frutos por visita do que aquelas que se utilizaram da estratégia de estolar, colhendo um fruto por visita. 
Tabela I. Aves observadas alimentando-se dos frutos de Miconia rubiginosa no cerradão da Estação Experimental de Itirapina, Itirapina, São Paulo, no período de 28/02 a 20/03 de 1985 (A, alcançar; C, colher; E, estolar; I, engole inteiro; MI, masca e engole inteiro; MP, masca e engole um pedaço do fruto). O Potencial representa a avaliação subjetiva da importância da espécie na dispersão das sementes, sendo $\mathrm{G}$, grande; $\mathrm{M}$, média; $\mathrm{P}$, pequena.

\begin{tabular}{lcccc}
\hline Espécie & Coleta & Ingestão & $\begin{array}{l}\mathrm{n}^{\circ} \text { de indivíduos } \\
\text { por visita alimentar }\end{array}$ & Potencial \\
\hline Elaenia flavogaster & $\mathrm{C}$ & $\mathrm{I}$ & 1 & $\mathrm{P}$ \\
Pitangus sulphuratus & $\mathrm{E}$ & $\mathrm{I}$ & 1 & $\mathrm{P}$ \\
Myiodynastes maculatus & $\mathrm{E}$ & $\mathrm{I}$ & 1 & $\mathrm{P}$ \\
Tyrannus melancholicus & $\mathrm{E}$ & $\mathrm{I}$ & 1,3 & $\mathrm{P}$ \\
Pachyramphus validus & $\mathrm{E}$ & $\mathrm{I}$ & 1 & $\mathrm{M}$ \\
Turdus rufiventris & $\mathrm{A}$ & $\mathrm{I}$ & 1,2 & $\mathrm{G}$ \\
Turdus leucomelas & $\mathrm{C}$, & $\mathrm{I}$ & 1,2 & $\mathrm{P}$ \\
Turdus amaurochalinus & $\mathrm{C}$ & $\mathrm{I}$ & 1 & $\mathrm{P}$ \\
Nemosia pileata & $\mathrm{C}$ & $\mathrm{MP}$ & 1 & $\mathrm{P}$ \\
Thraupis sayaca & $\mathrm{A}$ & $\mathrm{MI}$ & 1 & 1,2 \\
Tangara cayana & $\mathrm{A}$ & $\mathrm{MP}$ & & \\
\hline
\end{tabular}

Foram observados poucos encontros agonísticos interespecíficos e intraespecíficos. Um exemplar de T. leucomelas perseguiu outro expulsando-o da árvore e um T. amaurochalinus efetuou um ataque de substituição sobre um T. leucomelas, ocasionando sua fuga. As aves de nenhuma das espécies observadas que visitaram a planta permaneceram mais que o tempo necessário para se alimentar; a que mais visitou e mais frutos comeu por visita foi T. leucomelas, sendo provavelmente a melhor dispersora de M. rubiginosa.

\section{DISCUSSÃO}

As melastomatáceas produzem frutos que se caracterizam por serem dispersos por aves, de tamanho médio ou pequeno, não especializadas (SNOw, 1981). As plantas estudadas estavam em uma pequena mancha de cerradão, sendo sua dispersão efetuada apenas por pássaros oportunistas. Como os frutos das melastomatáceas são ricos em carboidratos e possuem sementes pequenas ( SNOw $_{1}$ 1981), os pássaros que se alimentam de invertebrados (SICK, 1997) teriam condições de balancear sua alimentação ingerindoos. Assim, a estratégia de produzir muitas sementes pequenas, garantiria sua dispersão por pássaros oportunistas. MoERMOND \& DeNSLOw (1985) consideram que uma subdivisão dos frugívoros em especialistas e generalistas/oportunistas estaria sujeita a contradições e inconsistências.

As aves observadas, ou engoliram, ou mascaram o fruto. Seriam melhores dispersoras aquelas que engolem os frutos inteiros, uma vez que todas as sementes contidas no fruto são levadas pelas aves e dispersas longe das árvores produtoras. As mascadoras engolem menor número de sementes, pois as separam da polpa, deixando-as cair sob a árvore. Os pássaros das famílias Tyrannidae e Muscicapidae são normalmente engolidores, portanto melhores dispersores, enquanto os da família Emberizidae são mascadores, não sendo dispersores tão eficientes (MoERMOND \& DensLow, 1983), embora se alimentem de maior quantidade de frutos por visita, conseguindo assim maior 
quantidade de energia e carregando menor volume de sementes, que mais tarde seriam eliminadas, não fornecendo a eles ganho nenhum de energia (Levey, 1987). Nos dois casos, tanto as aves mascadoras como as engolidoras de frutos engolem pedaços de polpa com sementes pequenas, o que representa uma estratégia da planta para assegurar a dispersão e oferecer proteção contra predação de sementes (JANZEN, 1971; 1983). Desta forma, há alimento para as aves e maior eficiência do processo de dispersão, pois haverá mais sementes ingeridas (TREJo-PÉrEZ, 1976), o que aumenta a probabilidade de que as mesmas sejam eliminadas junto com as fezes, em locais favoráveis à germinação.

A abundância de recursos alimentares oferecidas por M. rubiginosa é, provavelmente, o fator responsável pelo reduzido número de aves que apresentam reações agonísticas (LECK, 1972). Os poucos encontros agressivos observados se deram entre espécies do mesmo gênero.

Agradecimentos. À Fundação MB que financiou as viagens a Itirapina. Ao Prof. Dr. Wesley Rodrigues Silva pela ajuda no campo. À administração da Estação Experimental de Itirapina, Instituto Florestal do Estado de São Paulo. Ao Prof. Dr. Marcio Zikan Cardoso, Unicamp pela revisão do abstract.

\section{REFERÊNCIAS BIBLIOGRÁFICAS}

Cetesb. 1992. São Paulo: perfil ambiental e estratégias. São Paulo, Governo do Estado. 60p. Hilty, S. T. 1980. Flowering and fruting periodicity in a premontane rain forest in pacific Colombia. Biotropica, Washington, 12(4):292-306.

Janzen, D. H. 1971. Seed predation by animals. Ann. Rev. Ecol. Syst., Palo Alto, 2:465-492.

- 1983. Dispersal of seeds by vertebrate guts. In: FutuYMA, D. T. \& Slatkin, M. eds. Coevolution. Sunderland, Sinauer. p. 232-262.

Leck, C. F. 1972. The impact of some North American migrants at fruiting trees in Panama. Auk, Washington, 89:842-850.

Levey, D. T. 1987. Seed size and fruit-handling techniques of avian frugivores. Am. Nat., Chicago, 12(4):471-485.

Martins, A. B.; Semir, J. et al. 1996. O gênero Miconia Ruiz \& Pav. (Melastomataceae) no Estado de São Paulo. Acta bot. bras., São Paulo, 10(2):267-316.

Moermond, T. C. \& Denslow, J. S. 1983. Fruit choice in neotropical birds: effects of fruit type and accessibility on selectivity. J. Anim. Ecol., London, 52:407-420.

-_ 1985. Neotropical avian frugivores: patterns of behavior, morphology, and nutrition, with consequences for fruit selection. Ornithological Monographs, Washington, 36:865-897.

Sick, H. 1997. Ornitologia brasileira. Rio de Janeiro, Nova Fronteira. 861p.

SNOw, D. W. 1981. Tropical frugivorous birds and their food plants: a world survey. Biotropica, Washington, 13(1):1-14.

Trejo-Pérez, L. 1976. Diseminación de semillas por aves en "Los Tuxtlas". In: Gomez-Compa, A.; Vasquez-Yanes, C. et al. eds. Regeneración de Selvas. México, Continental. 676p.

Recebido em 25.09.2000; aceito em 05.07.2002. 